\title{
Usefulness of the orbicularis oculi myocutaneous flap in periorbital reconstruction
}

\author{
Geon Woo Kim ${ }^{1}$, \\ Yong Chan $\mathrm{Bae}^{1,2}$, \\ Joo Hyoung Kim ${ }^{1}$, \\ Su Bong Nam ${ }^{1}$, \\ Hoon Soo Kim ${ }^{3}$ \\ ${ }^{1}$ Department of Plastic and \\ Reconstructive Surgery, Pusan National \\ University School of Medicine, Busan; \\ ${ }^{2}$ Biomedical Research Institute and \\ ${ }^{3}$ Department of Dermatology, Pusan \\ National University Hospital, Busan, \\ Korea
}

\begin{abstract}
Background: The esthetic and functional outcomes of periorbital defect reconstruction are very important because of the complex anatomy and specialized functions of this region. The orbicularis oculi myocutaneous (OOMC) flap is useful for the reconstruction of periorbital defects. But, according to the location and depth of the defects, the reconstruction using OMC flaps with various techniques is rare. The authors have used various kinds of OOMC flaps in various situations and we present an analysis of our experiences.

Methods: From November 2001 to July 2017, we used 36 00MC flaps to reconstruct 30 periorbital defects in 25 patients. We analyzed the cause of the defect, its location, the type of concomitant surgery, the method of flap movement, and complications.

Results: Of the 30 defects, basal cell carcinoma was the most common cause, accounting for 20 cases. When the used 00MC flap was classified according to the location of the defects, the switch flap was used in nine cases among 15 defects of lower eyelid, and the V-Y advancement flap was mainly used for other parts. As surgical methods according to the depth of defect were classified, all cases involving the tarsal plate were reconstructed with a composite graft. In case of skin and muscles, they were reconstructed only with OOMC flap or with full-thickness skin graft.

Conclusion: The OOMC flap provides good skin quality that is very similar to that of the defect tissue. Depending on the location and depth of the defect, the OOMC flap may be used properly in a variety of ways to achieve good results.
\end{abstract}

Keywords: Myocutaneous flap / Surgical flaps / Myocutaneous flaps

\section{INTRODUCTION}

The reconstruction of periorbital region defects requires an elaborate approach that takes into account the complex anatomy of the region, as well as functional aspects. Since the eyelid skin is thin and functionally important, reconstruction using the surrounding eyelid tissue is superior in terms of color match or texture, rather than using other tissue. Moreover, for

\footnotetext{
Correspondence: Yong Chan Bae

Department of Plastic and Reconstructive Surgery, Pusan National University

School of Medicine and Biomedical Research Institute, Pusan National University

Hospital, 179 Gudeok-ro, Seo-gu, Busan 49241, Korea

E-mail: baeyc2@hanmail.net

Received July 12, 2018 / Revised October 9, 2018 / Accepted October 16, 2018
}

optimal results, the flap must resemble normal tissue in terms of structure, shape, thickness, and mobility [1].

Many studies have recently been carried out on procedures using the orbicularis oculi myocutaneous (OOMC) flap. The orbicularis oculi muscle surrounds the palpebral fissure and consists of the orbital, pretarsal, and preseptal orbicularis. The upper and the lower eyelids are similar in structure, making it easier to transform tissues from adjacent regions to match the area of the defect [2]. The OOMC flap also provides an abundant blood supply and high stability, and is therefore used with increasing frequency.

But, according to the location and depth of the defects, the reconstruction using OMC flaps with various techniques is rare. 
This study was conducted to investigate the benefits of the OOMC flap in the reconstruction of periorbital region defects by analyzing the outcomes of operations in 25 patients.

\section{METHODS}

\section{Study subjects}

This study was conducted on 36 OOMC flaps used in 30 defects in 25 patients who underwent reconstructive procedures for periorbital region defects between November 2001 and July 2017. All operations were conducted in Pusan National University Hospital and were performed by a single plastic surgeon (Y.C.B.). The medical records of each patient were retrospectively reviewed to identify the etiology of the defects, their location, the type of accompanying procedure, the method of flap movement, and complications. The patients were followed up from 6 months to 5 years postoperatively (mean, 32 months), and no patients were lost to follow up or died. Twelve patients were male and 13 were female. They ranged in age from 18 to 87 years, and the average and median ages were 64 years and 68 years, respectively.

\section{Operative procedure}

The procedure can be performed under either local or general anesthesia. The defect is first measured and a flap of adequate size is marked on the upper eyelid, similar to the upper blepharoplasty. If the depth is localized to the skin and muscle, the OOMC flap alone can be used as a cover, whereas the tarsal plate is involved, a composite graft is used with the OOMC flap. The flaps lower margin is placed either on the innate supratarsal fold or, in cases without a fold, at $7 \mathrm{~mm}$ above the eyelid margin (Fig. 1) [3]. An appropriately sized flap is then marked on the upper or lower eyelid, similar to the upper or lower blepharoplasty design used in the surgical treatment of dermatochalasis. The flap is then incised through the skin and preseptal and orbicularis oculi muscle down to the level of orbital septum. The flap elevated from lateral to medial, with the flap remaining in continuity with the medial fat pocket. Care must be taken at this point to avoid detaching the orbicularis oculi muscle from the bed, so that the muscular perforator of the peripheral arcade may be preserved as the pedicle. Once flap elevated, it can be rotated on its pedicle into a defect in a variety of locations. The technique using subdermal tunnel was not used. The flap is then inset after it is tailored to fit the shape of the defect. The donor site is closed as in a standard upper blepharoplasty.

\section{RESULTS}

Basal cell carcinoma (BCC) was the most common cause, accounting for the defects in 20 cases. Six cases were caused by xanthoma, two cases by squamous cell carcinoma, and two cases by coloboma. Fifteen defects were on the lower eyelid, eight defects on the upper eyelid, five defects in the medial canthal region, and two defects in the lateral canthal region. When a defect involved two or more locations, it was classified as being in the location where the defect was predominant. Among the 36 OOMC flaps used to reconstruct the defects, 24 were reconstructed using only the OOMC flap, six were reconstructed using full-thickness skin graft with OOMC flap, and six were reconstructed using a simultaneous composite graft with OOMC flap.

Among the OOMC flap types used, the V-Y advancement type was used in 18 cases, a switch flap in 10 cases (seven unipedicled and three bipedicled), a pivot flap in six cases, and simple advancement in two cases. No cases of necrosis of the flap were reported, and there were one case of cancer recur-
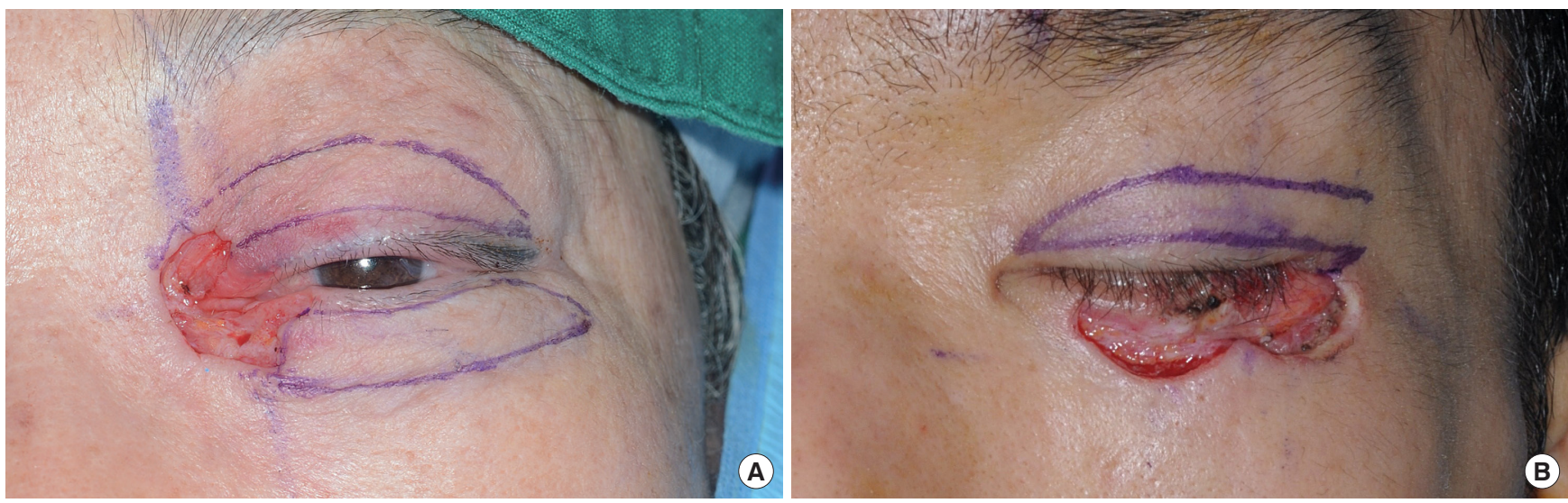

Fig. 1. Various design methods of orbicularis oculi myocutaneous flap. (A) Design for V-Y advancement myocutaneous flap. (B) Design for switch flap. 
Table 1. Summary of patients $(n=25)$

\begin{tabular}{|c|c|c|c|c|c|c|c|}
\hline Patient & Sex & Age (yr) & Etiology & Location of defect & Depth of defect & Surgical technique & Complication \\
\hline 1 & Female & 52 & $\mathrm{BCC}$ & Lower eyelid & Tarsal plate & Switch+composite graft & Entropion \\
\hline 2 & Female & 82 & $\mathrm{BCC}$ & Upper eyelid & Muscle & $\begin{array}{l}\text { V-Y advancement } \\
\text { Switch }\end{array}$ & $\begin{array}{l}\text { None } \\
\text { None }\end{array}$ \\
\hline 3 & Female & 63 & $\mathrm{BCC}$ & Lower eyelid & Tarsal plate & Switch+composite graft & Reccurence \\
\hline 4 & Female & 53 & $\mathrm{BCC}$ & Lower eyelid & Tarsal plate & Switch+composite graft & None \\
\hline 5 & Male & 69 & $\mathrm{BCC}$ & Medial canthus & Skin & V-Y advancement+FTSG & None \\
\hline 6 & Male & 43 & $\mathrm{BCC}$ & Lower eyelid & Skin & Switch & None \\
\hline 7 & Male & 67 & SCC & Lower eyelid & Tarsal plate & Switch+composite graft & None \\
\hline 8 & Male & 72 & SCC & Lower eyelid & Tarsal plate & Switch+composite graft & None \\
\hline 9 & Female & 87 & $\mathrm{BCC}$ & Lateral canthus & Muscle & Pivot & None \\
\hline 10 & Male & 62 & $\mathrm{BCC}$ & Lower eyelid & Skin & Switch & None \\
\hline 11 & Male & 75 & $\mathrm{BCC}$ & Upper eyelid & Muscle & $V-Y+F T S G$ & None \\
\hline 12 & Female & 18 & Coloboma & $\begin{array}{l}\text { Lower eyelid } \\
\text { Lower eyelid }\end{array}$ & Skin & $\begin{array}{l}\text { Pivot } \\
\text { Pivot }\end{array}$ & $\begin{array}{l}\text { None } \\
\text { None }\end{array}$ \\
\hline 13 & Male & 48 & $\mathrm{BCC}$ & Medial canthus & Muscle & $\begin{array}{l}\text { V-Y advancement } \\
\text { V-Y advancement }\end{array}$ & $\begin{array}{l}\text { None } \\
\text { None }\end{array}$ \\
\hline 14 & Female & 53 & $\mathrm{BCC}$ & Lower eyelid & Skin & V-Y advancement & None \\
\hline 15 & Male & 71 & $\mathrm{BCC}$ & Lateral canthus & Muscle & V-Y advancement+FTSG & None \\
\hline 16 & Male & 74 & $\mathrm{BCC}$ & $\begin{array}{l}\text { Upper eyelid } \\
\text { Lower eyelid }\end{array}$ & Muscle & $\begin{array}{l}\text { Pivot } \\
\text { Simple advancement }\end{array}$ & $\begin{array}{l}\text { None } \\
\text { None }\end{array}$ \\
\hline 17 & Male & 56 & Xanthoma & $\begin{array}{l}\text { Lower eyelid } \\
\text { Upper eyelid }\end{array}$ & $\begin{array}{l}\text { Muscle } \\
\text { Skin }\end{array}$ & $\begin{array}{l}\text { Pivot } \\
\text { Simple advancement }\end{array}$ & $\begin{array}{l}\text { None } \\
\text { None }\end{array}$ \\
\hline 18 & Female & 55 & Xanthoma & Upper eyelid (×2) & Skin & V-Y advancement $(\times 2)$ & None \\
\hline 19 & Female & 68 & $\mathrm{BCC}$ & Lower eyelid & Orbital septum & Pivot+FTSG & None \\
\hline 20 & Female & 75 & $\mathrm{BCC}$ & Lower eyelid & Orbital septum & $\begin{array}{l}\text { Switch } \\
\text { V-Y advancement }\end{array}$ & $\begin{array}{l}\text { None } \\
\text { None }\end{array}$ \\
\hline 21 & Male & 55 & Xanthoma & Upper eyelid (×2) & Skin & V-Y advancement $(\times 2)$ & None \\
\hline 22 & Male & 80 & $\mathrm{BCC}$ & Lower eyelid & Tarsal plate & Switch+composite graft & None \\
\hline \multirow[t]{2}{*}{23} & Female & 67 & $\mathrm{BCC}$ & Medial canthus & Skin & V-Y advancement & None \\
\hline & & & & & & V-Y advancement & None \\
\hline \multirow[t]{2}{*}{24} & Female & 68 & $\mathrm{BCC}$ & Medial canthus & Skin & V-Y advancement & None \\
\hline & & & & & & V-Y advancement & None \\
\hline 25 & Female & 84 & $\mathrm{BCC}$ & Medial canthus & Muscle & $\begin{array}{l}\text { V-Y advancement+FTSG } \\
\text { V-Y advancement+FTSG }\end{array}$ & $\begin{array}{l}\text { None } \\
\text { None }\end{array}$ \\
\hline
\end{tabular}

BCC, basal cell carcinoma; FTSG, full-thickness skin graft; SCC, squamous cell carcinoma.

Table 2. Classification of OOMC flaps used according to location of defects

\begin{tabular}{lcccc}
\hline Variable & Switch flap & Pivot flap & $\begin{array}{c}\text { V-Y } \\
\text { advancement } \\
\text { flap }\end{array}$ & $\begin{array}{c}\text { Simple } \\
\text { advancement } \\
\text { flap }\end{array}$ \\
\hline Lower eyelid & 9 & 4 & 2 & 1 \\
Upper eyelid & 1 & 1 & 6 & 1 \\
Medial canthus & - & - & 9 & - \\
Lateral canthus & - & 1 & 1 & - \\
Total & 10 & 6 & 18 & 2 \\
\hline
\end{tabular}

OOMC, orbicularis oculi myocutaneous.

rence and one case of entropion (Table 1).

When the used OOMC flap was classified according to the location of the defects, the switch flap was used in nine cases among 15 defect of lower eyelid, and the V-Y advancement flap was mainly used for other parts (Table 2). As surgical methods according to the depth of defect were classified, all cases involving the tarsal plate were reconstructed with a composite graft. In case of skin and muscle, reconstruction with OOMC flap
Table 3. Classification of reconstruction method according to depth of defects

\begin{tabular}{lccc}
\hline Variable & OOMC flap & $\begin{array}{c}\text { OOMC flap } \\
+ \text { FTSG }\end{array}$ & $\begin{array}{c}\text { OOMC flap } \\
+ \text { composite graft }\end{array}$ \\
\hline Skin & 14 & 1 & - \\
Orbicularis oculi muscle & 8 & 4 & - \\
Orbital septum & 2 & 1 & - \\
Tarsal plate & - & - & 6 \\
Total & 24 & 6 & 6 \\
\hline
\end{tabular}

OOMC, orbicularis oculi myocutaneous; FTSG, full-thickness skin graft.

alone or accompanied by full-thickness skin graft (Table 3).

A 55-year-old female patient had a large xanthoma on the medial side of both upper eyelids (Fig. 2A), so we removed this xanthoma and reconstructed the defect with a V-Y advancement flap from the lateral side (Fig. 2B, C). No surgical revision of the scar was needed, and the patient's satisfaction and functional outcomes were both high (Fig. 2D).

A 75-year-old female patient underwent Mohs micrographic 
surgery (MMS) for BCC on the left lower eyelid (Fig. 3A). The lower eyelid was reconstructed with a laterally based unipedicled OOMC flap from the upper eyelid, with a simultaneous $\mathrm{V}-\mathrm{Y}$ advancement OOMC flap from the lateral side of the lower eyelid (Fig. 3B). Three weeks after operation, flap division was performed. No local recurrence or metastasis occurred during 10 months of follow-up (Fig. 3C). There was no flap necrosis, no complications such as entropion or ectropion, and the patient was cosmetically satisfied.

A 53-year-old female patient underwent excision for BCC on the right lower eyelid (Fig. 4A). Because it was a full-thickness defect, it was reconstructed with a septal mucochondral composite graft and a laterally based unipedicled OOMC flap. Twenty-nine days after the operation (Fig. 4B), flap division was performed. Two years later, BCC recurred, and she additionally underwent MMS for BCC on the left lower eyelid. The lower eyelid was reconstructed with a median forehead flap and STSG.

\section{DISCUSSION}

Defects in the periorbital region have various etiologies and are found in different areas. BCC is the most common type of cancer that occurs especially on the upper eyelid, accounting for $90 \%$ of malignant tumors of the eyelid [4]. SCC is less common, but is often found on the lower eyelid and tends to be more aggressive. In addition, other defects occurred after operations for xanthoma and coloboma. Though BCC and SCC are commonly found in the facial area due to sunlight exposure, they are normally limited to the skin margins of the eyelid, and do not usually spread to the eyelid margin and conjunctiva [1].

The skin of the eyelid is extremely thin and flexible, making
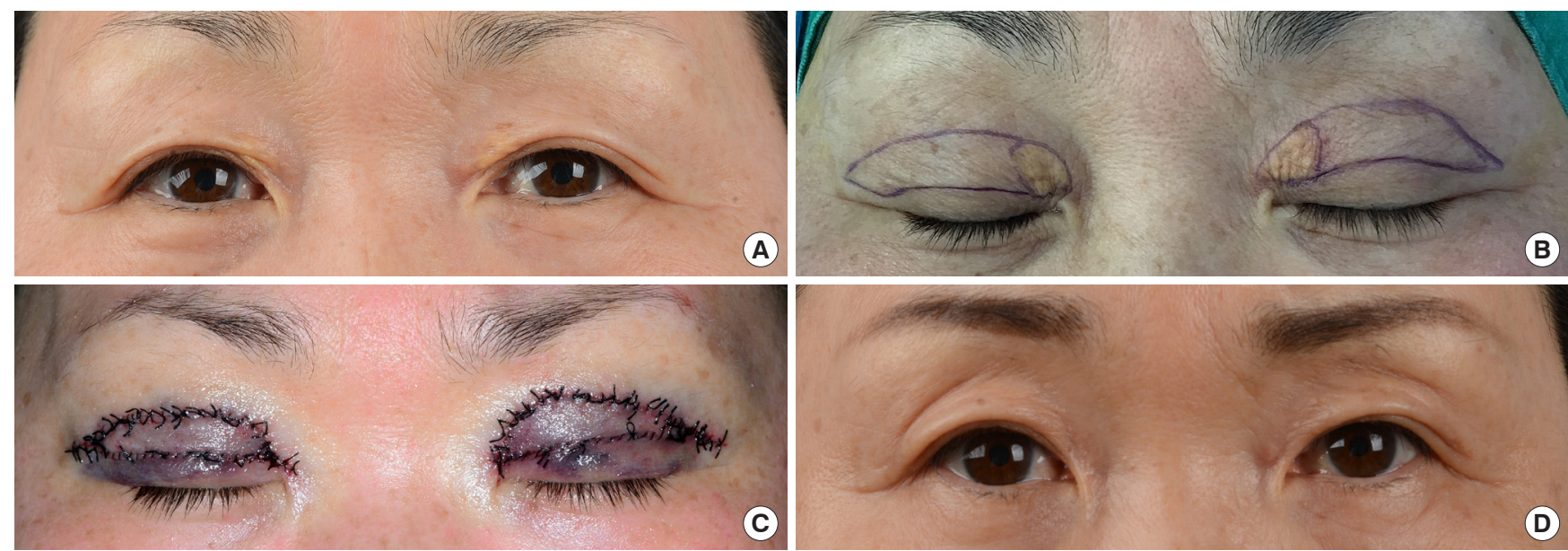

Fig. 2. Case 1. A V-Y advancement orbicularis oculi myocutaneous (OOMC) flap in a case of xanthoma. (A, B) Preoperative view of design for operation. (C) Immediate postoperative view. The OOMC flap (V-Y advancement OOMC flap). (D) Postoperative view of 6 months after reconstruction.
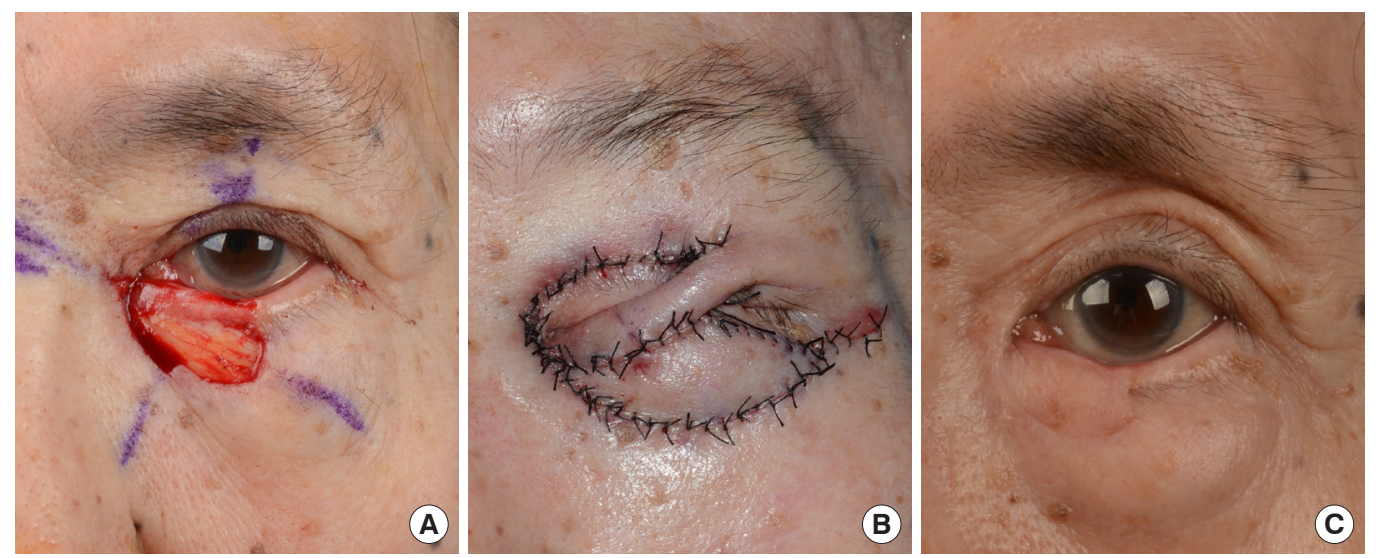

Fig. 3. Case 2. A V-Y advancement orbicularis oculi myocutaneous (OOMC) flap with an OOMC switch flap. (A) Post-Mohs micrographic surgery view. (B) Immediate postoperative view. The OOMC flap state (V-Y advancement OOMC flap+laterally based unipedicled OOMC switch flap). (C) Postoperative view of 10 months after reconstruction. 

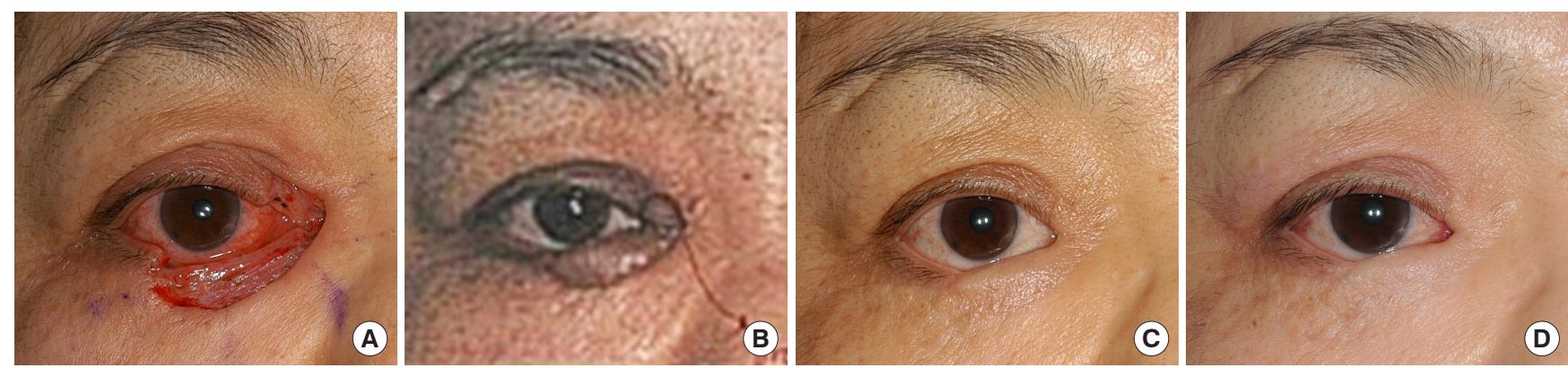

Fig. 4. Case 3. A composite graft with an orbicularis oculi myocutaneous (OOMC) switch flap. (A) Preoperative view of basal cell carcinoma on the right lower eyelid. (B) Preoperative view before flap division (29 days postoperatively; septal mucochondral composite graft+laterally based unipedicled OOMC switch flap). (C) Preoperative view before the second flap division (5 months postoperatively). (D) Postoperative view of 3 years after reconstruction.

the reconstruction of periorbital region defects particularly complex [5]. In particular, reconstruction of the upper eyelid is more challenging than that of the lower eyelid since it requires appropriate tissue from the surrounding region, natural mobility, contour, and proper cover and protection of the eyeball. In contrast, for reconstruction of the lower eyelid, it is possible to choose from various methods by considering the skin and muscle layers as a single layer and the tarsal plate and conjunctiva as another, thereby choosing the type of method to be used for each layer [6].

When presented with an eyelid defect, the surgeon should analyze the missing lamellar components and whether canthal support is compromised. Anterior lamella defect is mainly caused by involvement of skin and orbicularis oculi muscle, so reconstruction is usually done through skin graft or local flap. If there is a posterior lamella defect, composite graft, tarsoconjunctival flap, conjunctival graft and mucosal graft are used.

Different reconstructive methods can be applied depending on the depth and the size of the defect area. If the area is limited to the skin and muscle, an OOMC flap is sufficient for reconstruction, while other reconstruction technique such as composite graft is used together with an OOMC flap if the defect involve full layer. Additionally, if the defect area is wider, as in case 3 (Fig. 4), the palpebral fissure should be covered with the OOMC flap to maintain its aesthetic and functional properties, while the remaining area can be covered by a different flap.

Many different methods have been adopted to reconstruct defects of the periorbital region. The very first lower eyelid reconstructive procedure using a pedicled scalp flap was performed in 1898. Hughes described a tarsoconjunctival flap that used the upper eyelid tarsus and conjunctiva as a hematogenous flap, and Mustarde presented the reconstruction of the lower eyelid with a composite graft of nasal septal cartilage and mucosa. Jones, Gorney, and Orticochea used an upper eyelid full-thickness flap for reconstructing the lower eyelid, and Jack- son used a similar technique for Treacher-Collins syndrome [6]. Multiple composite eyelid grafts, the Cutler-Beard flap, the inferiorly based tarsoconjunctival flap, the tarsoconjunctival rotational flap, the tarsoconjunctival horizontal advancement flap, and medial or temporal forehead flaps are also used for reconstruction of the upper eyelid, although severe side effects such as ectropion, entropion, and hypofunction are common in these methods [7-9].

OOMC flaps contain skin, subcutaneous fat, and muscle with sufficient thickness and provide excellent color and texture $[10,11]$. The myofibers of the flap preserve a consistent muscle tone, which plays a crucial role in helping the eyelid maintain contact with the eyeball. Successful surgery using this flap depends on a sufficient supply of arterial blood, where the arterial system that branches from the supraorbital, superficial temporal, angular, and transverse facial arteries forms an abundant blood stream [1].

In our results, OOMC flaps provided a similar tissue thickness to that of the tissues surrounding the defect area, and did not cause any complications such as depression or ectropion. In some cases, congestion was observed 1-2 days after the operation, but normally disappeared over time. In one of the two cases of complications, a patient who had a recurrence of cancer underwent another operation using a medial forehead flap and a split-thickness skin graft after MMS, and flap division was then performed. In the patient who experienced entropion, the area of skin that was inverted toward the conjunctiva and parts of the implanted cartilage were removed to prevent the recurrence of entropion.

However, this method has limited applicability if the defect is too large, since the remaining orbicularis oculi muscle is needed for reconstruction. Additionally, careful and meticulous dissection is required for the pedicle of the OOMC flap to be preserved. In conclusion, OOMC flaps are an effective method of reconstructing periorbital region defects by providing skin 
quality similar to that of the defect area and an abundant blood supply, as well as by enabling primary closure of the donor site and tailored reconstruction using various methods to fit the location and the depth of the defect area.

\section{CONFLICT OF INTEREST}

No potential conflict of interest relevant to this article was reported.

\section{PATIENT CONSENT}

The patients provided written informed consent for the publication and the use of their images.

\section{ORCID}

Geon Woo Kim https://orcid.org/0000-0002-5467-9480

Yong Chan Bae https://orcid.org/0000-0002-0268-4667

Joo Hyoung Kim https://orcid.org/0000-0002-4893-3761

Su Bong Nam https://orcid.org/0000-0003-2718-2230

Hoon Soo Kim https://orcid.org/0000-0002-7649-1446

\section{REFERENCES}

1. Demir Z, Yuce S, Karamursel S, Celebioglu S. Orbicularis oculi myocutaneous advancement flap for upper eyelid reconstruction. Plast Reconstr Surg 2008;121:443-50.

2. Kim SW, Han HH, Jung SN. Orbicularis oculi myocutaneous island flap for upper eyelid reconstruction. J Craniofac Surg 2012;23:746-8.
3. Han J, Kwon ST, Kim SW, Jeong EC. Medial and lateral canthal reconstruction with an orbicularis oculi myocutaneous island flap. Arch Plast Surg 2015;42:40-5.

4. Maghsodnia G, Ebrahimi A, Arshadi A. Using bipedicled myocutaneous Tripier flap to correct ectropion after excision of lower eyelid basal cell carcinoma. J Craniofac Surg 2011;22: 606-8.

5. Greco M, Vitagliano T, Fiorillo MA, Greto Ciriaco A. A new technique of upper eyelid blepharoplasty using the orbicularis muscle flap. Aesthetic Plast Surg 2012;36:18-22.

6. Bae YC, Kim SH, Hwang SM, Kim KT, Oh CK. Reconstruction of the lower eyelid with septal mucochondral composite graft and upper eyelid musculocutaneous flap. J Korean Soc Plast Reconstr Surg 2004;31:309-14.

7. Kersten RC, Anderson RL, Tse DT, Weinstein GL. Tarsal rotational flap for upper eyelid reconstruction. Arch Ophthalmol 1986;104:918-22.

8. Tirone L, Schonauer F, Sposato G, Molea G. Reconstruction of lower eyelid and periorbital district: an orbicularis oculi myocutaneous flap. J Plast Reconstr Aesthet Surg 2009;62:1384-8.

9. Porfiris E, Kalokerinos D, Christopoulos A, Damilakos P, Ioannidis A, Georgiou P. Upper eyelid island orbicularis oculi myocutaneous flap for periorbital reconstruction. Ophthalmic Plast Reconstr Surg 2000;16:42-4.

10. d'Alcontres FS, Cuccia G, Lupo F, Delia G, Romeo M. The orbicularis oculi muscle flap: its use for treatment of lagophthalmos and a review of its use for other applications. J Plast Reconstr Aesthet Surg 2010;63:416-22.

11. Moschella F, Cordova A. Upper eyelid reconstruction with mucosa-lined bipedicled myocutaneous flaps. Br J Plast Surg 1995;48:294-9. 